
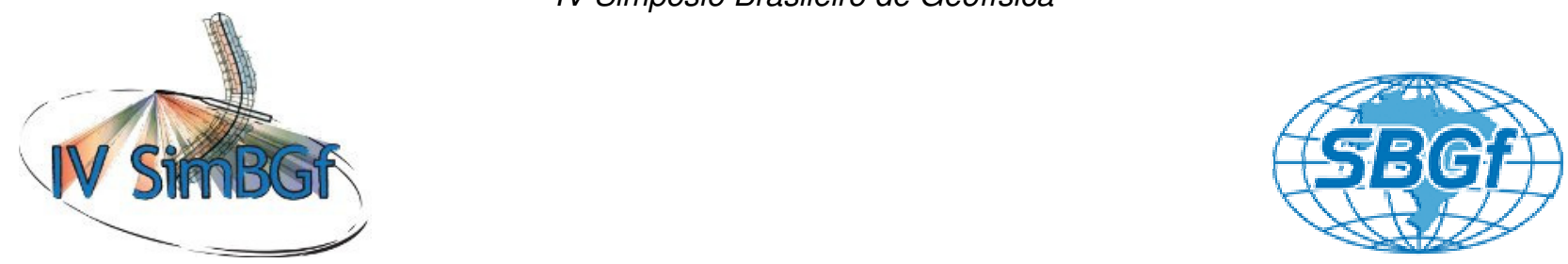

\title{
Cartografia geológica digital da Folha Ipú (SB-24-V-A-III) a partir da integração de dados geológicos pré-existentes e aerogeofísica
}

Verena Bispo Torres ${ }^{1}$, Marcia Valadares dos Santos ${ }^{1}$, Camila Nascimento Alves ${ }^{1}$, Francisco de Assis Matos de Abreu

1-Faculdade de Geologia - Instituto de Geociências - Universidade Federal do Pará - UFPA

Copyright 2010, SBGf - Sociedade Brasileira de Geofísica

Este texto foi preparado para a apresentação no IV Simpósio Brasileiro de Geofísica, Brasília, 14 a 17 de novembro de 2010. Seu conteúdo foi revisado pelo Comitê Técnico do IV SimBGt, mas não necessariamente representa a opinião da SBGf ou de seus associados. É proibida a reprodução total ou parcial deste material para propósitos comerciais sem prévia autorização da SBGf.

\section{Resumo}

A província Borborema é considerada uma colcha de retalhos de terrenos de diferentes litologias, de idades distintas, separados por falhas e lineamentos importantes.

As imagens aerogeofísicas forneceram informações preliminares sobre o comportamento regional, em superfície e sub-superfície das feições geológicas presentes na Folha Ipú. A partir das imagens aeromagnetométricas foi possível identificar que os trends magnéticos principais orientam-se NE-SW. As imagens aerogamaespectrométricas possibilitaram principalmente a individualização dos corpos ígneos presentes nesta região.

A interpretação dos produtos de sensoriamento remoto e aerogeofísicos, associadas ao mapeamento geológico na escala de 1:100.000 da Folha Ipú permitiram a caracterização do padrão lito-estrutural desta região.

\section{Introdução}

A porção Noroeste do Ceará, onde se encontra a Região de Sobral, está inserida no contexto geológico da Província Borborema, denominação introduzida por Almeida et al. (1977), e aplicado para a parte leste da região nordeste da Plataforma Sul-Americana. A Província é considerada uma colcha de retalhos de terrenos de diferentes litologias, de idades distintas, separados por falhas e lineamentos importantes.

A cartografia geológica é um dos ramos da geologia que tem como objetivo estudar uma determinada área fazendo levantamentos que podem abranger diversos objetivos como tipo litológico, recursos minerais, hidrogeologia, etc. Dessa forma é uma ferramenta importante na geologia.

Com a finalidade de integrar os trabalhos de campo na área que abrange a Folha Ipú, este trabalho utilizou de análise de campo com o auxílio de informações retiradas a partir de sensores remotos, como imagens do Mosaico Geocover 2000, Radar SRTM (Shuttle Radar Topography Mission) e imagens Landsat TM e ETM, além do auxilio de imagens aerogeofisicas do Projeto Rio Acaraú foi possível a confecção de um mapa geológico em ambiente SIG (Sistema de Informação Geográfica).

A Aerogeofísica é um dos ramos das Geotecnologias que experimentou um dos maiores desenvolvimentos nos últimos anos, com contribuições importantes para o avanço do conhecimento geológico e a exploração mineral em todos os tipos de terreno (Souza Filho \& Crosta, 2003). Assim, associada com as imagens de satélites são importantes ferramentas para o estudo de uma determinada área.

\section{Metodologia/ Problema Investigado}

Para a realização do trabalho serão utilizados mapas geológicos da Folha Ipú na escala de 1:25.000 e em menor proporção em 1:50.000, frutos da execução de diversos estágios de mapeamento geológico, TCC, IC e dissertações de mestrado na região aludida;

Compatibilizada em ambiente computacional base planialtimétrica em 1:100.000, gerada pelo IBGE/SUDENE para o lançamento de todas as informações sistematizadas;

Produtos de sensores remotos (imagens Landsat em diferentes bandas e imagens de radar e fotografias aéreas) e imagens aerogeofísicas, para extração de lineamentos e delimitação dos contatos geológicos através de interpretação visual;

Checagens de campo para reduzir dúvidas e coletar dados complementares, quando se realizarão seções geológicas contínuas, previamente escolhidas, as quais acontecerão em Maio e julho/2010, durante atividades acadêmicas do IG-UFPA;

Balanceamento e uniformização das informações para a composição do mapa final do trabalho e da nota explicativa;

As ferramentas computacionais a serem utilizadas serão os programas ArcGis, Envi e Oasis Montaj.

A utilização de mapas aerogeofisicos de magnetometria e gamaespectrometria oriundo dos trabalhos do Contrato de Trabalho UFPA/CPRM/FADESP, são para uma melhor definição de domínios magnéticos e radiométricos. Os dados aerogeofísicos processados neste trabalho foram adquiridos do Projeto Rio Acaraú (1975), realizado na região NW do Ceará, onde foram levantados um total de $103,720.000 \mathrm{~km}$ de perfis a uma altura de vôo de $150 \mathrm{~m}$ controlada por radar-altímetro. As linhas de vôo deste projeto tem direções $\mathrm{N}-\mathrm{S}$, com espaçamentos entre linhas de 1000 e 500 metros e linhas de controle perpendiculares (E-W), com espaçamentos de $20 \mathrm{~km}$. A área total dos levantamentos foi de aproximadamente $59.000 \mathrm{~km}^{2}$.

A proposta apresentada busca suprir um banco de informações muito extenso já disponível sobre o NW do Ceará.

Resultados 
Com a finalidade de aperfeiçoar os trabalhos de melhor caracterização geológica, foi gerado o espectro de potência ponderado da área de trabalho, o qual mostra a freqüência de Nyquist a 0,5 ciclos por $\mathrm{Km}$, com a localização das fontes magnéticas infracrustais e supracrustais, também é possível ser observada neste espectro.

A imagem do campo magnético anômalo teve como finalidade a análise dos sinais que compunham o relevo do campo magnético anômalo. Assim pode-se demarcar padrões que individualizassem unidades com comportamento distintos.

Com a finalidade de ressaltar as estruturas magnéticas rasas foi elaborada a imagem de amplitude do sinal analítico (ASA).

Com os dados magnéticos foi possível a identificação de dois tipos de feições: unidades magnéticas e descontinuidades lineares. As unidades magnéticas compreendem corpos geológicos com magnetismo característico ou uniforme. Elas não coincidem necessariamente com as unidades geológicas (Figura 1 e 2).

As descontinuidades lineares, geralmente, são evidentes e representam falhas, fraturas ou tendências litológicas (Figura 3). Vale ressaltar que as respostas magnéticas são mais características de um grupo de rochas do que de litotipos individuais.

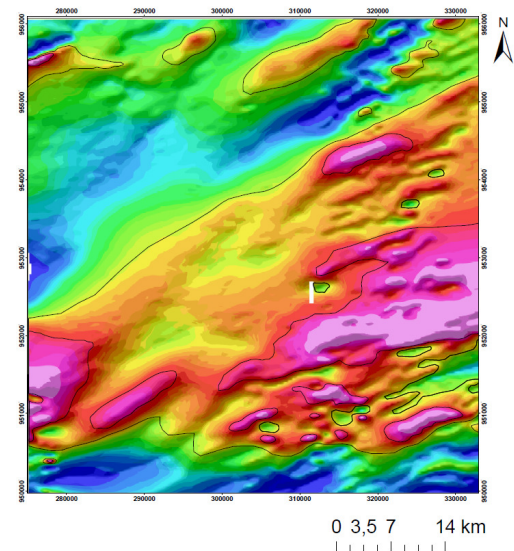

Figura 1 - Imagem do campo magnético anômalo da Folha Ipú separado em domínios.

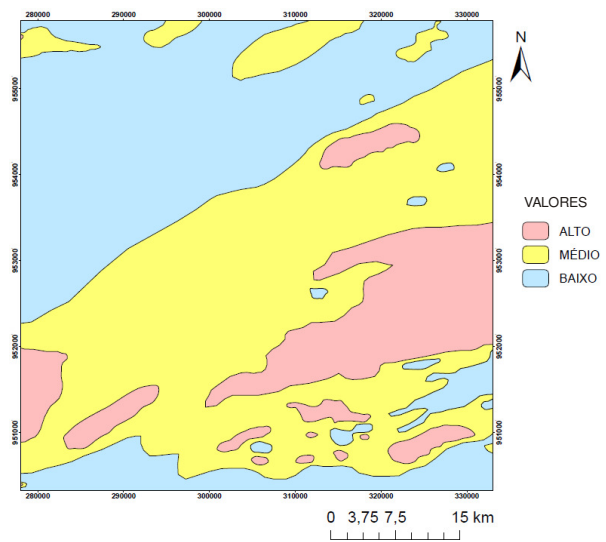

Figura 2 - Mapa de domínios magnéticos com valores

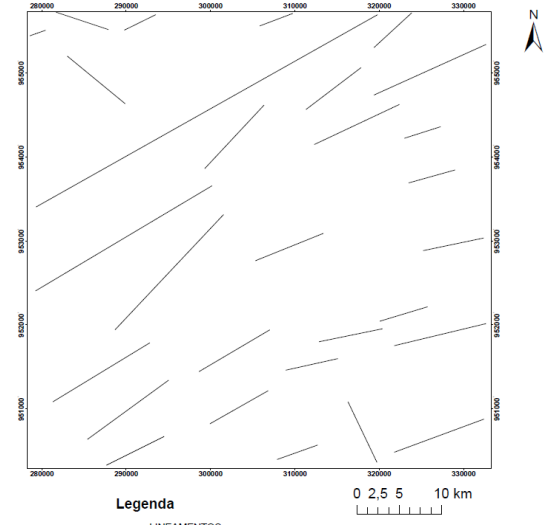

Figura 3 - Mapa de lineamentos magnéticos.

Os dados gamaespectrométricos aéreos foram processados com a finalidade de delimitar e diferenciar as variações dos litotipos existentes na região de trabalho. Os procedimentos efetuados sobre os dados gamaespectrometricos foram semelhantes aqueles adotados nos dados magnetométricos.

Foram confeccionadas após a etapa de micronivelamento as imagens individuais dos canais de $\mathrm{U}$, Th, $\mathrm{K}$ e Contagem Total.

$\mathrm{Na}$ interpretação de imagens gamaespectrométricas deve-se utilizar principalmente as variações relativas nas concentrações os radioelementos, para uma maior seletividade na interpretação.

O processo de interpretação é apoiado pelo uso de SIGs com atributos de processamento de imagens, que permite a integração desses dados com outros tipos de dados.

As interpretações de unidades gamaespectrométricas contribuem para a delimitação das unidades de mapeamento geológico, assim como de estruturas superficiais, além das anomalias fornecerem informações a cerca dos processos tectônicos envolvidos.

A imagem do canal de Potássio (Figura 4) mostra áreas com concentrações elevadas desse elemento, nas porções dos extremos noroeste e nordeste da imagem. Os dois pontos de maior concentração desse elemento encontram-se nas porções mais elevadas da área de trabalho.

A presença moderada desse elemento ao longo das regiões com drenagem mostra que esse elemento sofreu lixiviação.

Com relação a estruturação, observa-se uma tendência NE-SW para corpos, além de lineamentos seguindo esse mesmo padrão. 


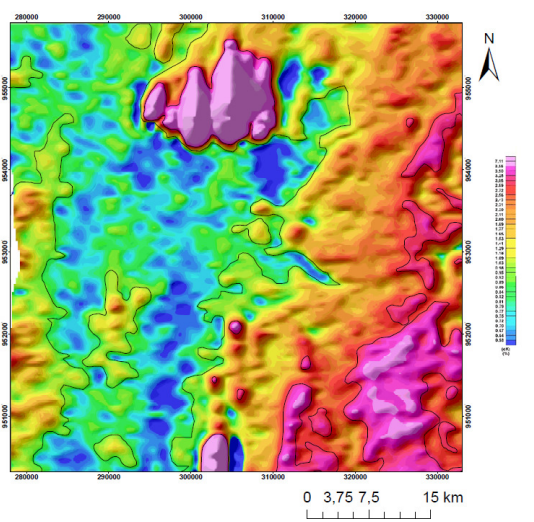

Figura 4 - Mapa radiométrico do canal K.

As imagens do canal de Urânio forneceram valores elevados desse elemento também nas porções mais elevadas da área como no canal de Potássio.

$\mathrm{Na}$ porção nordeste da área esses elemento forma feições arqueadas, com concentrações moderadas.

Ao longo da rede de drenagem principal da área esse elemento também é observado, com estruturação alongada, NE-SW.

A imagem da contagem total possibilitou uma definição do arranjo do arcabouço gamaespectrométrico regional. Nesta imagem foi possível observar que os grandes lineamentos delimitam várias unidades de mapeamento. Dentre elas se destacam o lineamento do lado oeste do mapa de direção NE-SW que secciona a área de trabalho.

A interpretação qualitativa das imagens aerogeofisicas foi feita no programa ArcGis 9.3. As imagens aerogamaespectrométricas também passaram por interpretação qualitativa e delas foram gerados mapas de domínios gamaespectrométricos dos canais de $\mathrm{U}, \mathrm{Th}, \mathrm{Ke}$ Contagem Total e um mapa com lineamentos (Figura 5).

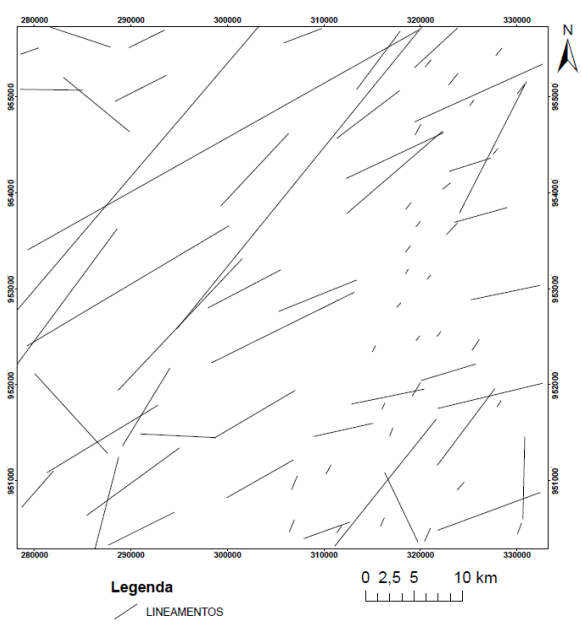

Figura 5 - Mapa com lineamentos aerogamaespectométricos.

\section{Discussão e Conclusões}

Foi possível realizar uma cartografia geológica digital dessa importante região nordestina que é o Noroeste do Ceará, mais precisamente a área abrangida pela Folha Ipú, em escala 1:100.000.

A aplicação de softwares, como o ArcGis, possibilitaram a transferência de dados analógicos para meio digital, além de possibilitarem a construção de um SIG da Folha Ipú.

As informações extraídas a partir das imagens de sensoriamento remoto e aerogeofisícas (aerogamaespectrometria e aeromagnetometria), a partir principalmente de interpretação visual, dão ao mapa geológico da Folha Ipú maior confiabilidade e credibilidade.

A interpretação dos produtos de sensoriamento remoto e aerogeofísicos, associadas ao mapeamento geológico na escala de 1:100.000 da Folha Ipú permitiram a caracterização do padrão lito-estrutural desta região.

As imagens aerogeofisicas forneceram informações preliminares sobre o comportamento regional, em superfície e sub-superfície das feições geológicas presentes na Folha Ipú. A partir das imagens aeromagnetométricas foi possível identificar que os trends magnéticos principais orientam-se NE-SW. As imagens aerogamaespectrométricas possibilitaram principalmente a individualização dos corpos ígneos presentes nesta região.

Com a interpretação dos dados de sensoriamento remoto e aerogeofísica foi possível elaborar um mapa geológico para a Folha Ipú (Figura 6).

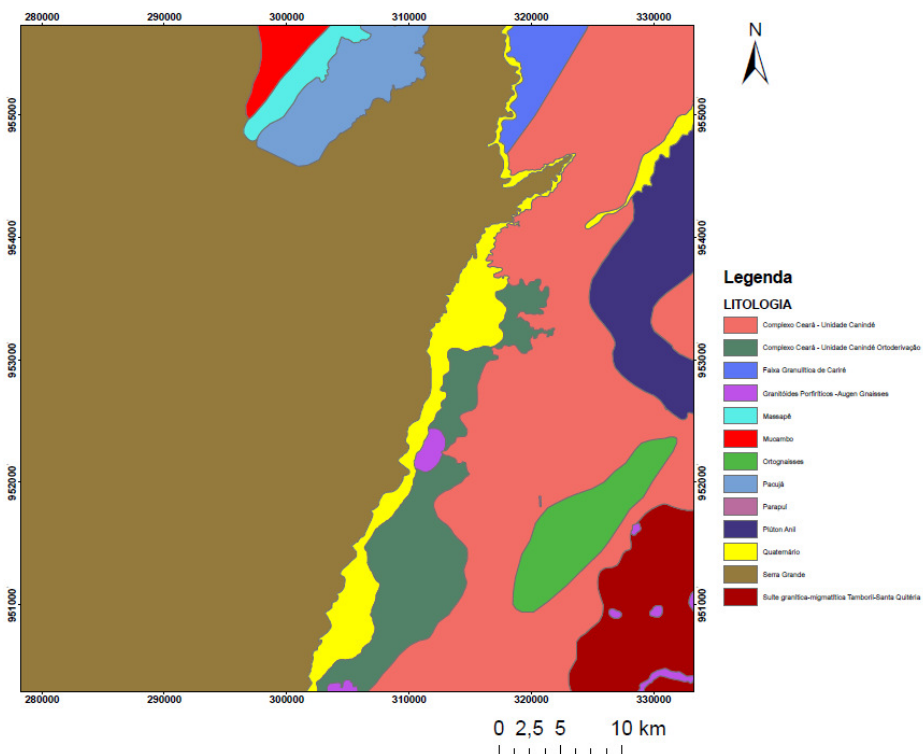

Figura 6 - Mapa de Unidades Geológicas gerado a partir da interpretação de dados aerogeofísicos.

Agradecimentos

Deus, Pibic-Ufpa, CPRM. 
Cartografia geológica digital da Folha Ipú (SB-24-V-A-III) a partir da integração de dados geológicos pré-existentes e 4 aerogeofísica

\section{Referências}

Almeida, F.F.M., Hasui, Y., Brito Neves, B.B., Fuck, R.A.

1977. Províncias Estruturais Brasileiras. 1977. In:

Sbg/Ne, Simp. Geol. Ne. Janeiro, 151-182 P.

Souza Filho, C. R. \& Crósta, A. P. 2003. Geotecnologias Aplicadas à Geologia. Revista Brasileira De Geociências. Volume 33. 